\title{
Physical inactivity in patients with COPD: the next step is ... action
}

\section{*Thierry Troosters ${ }^{1}$}

1 Department of Rehabilitation Sciences, KU Leuven, Leuven, Belgium; Respiratory Rehabilitation Division, University Hospital Gasthuisberg, Leuven, Belgium

*Professor Thierry Troosters, UZ Gasthuisberg, Respiratory Division, Herestraat 49, 3000 Leuven, Belgium

Tel: +3216330798 Fax: +3216330806

E-mail: thierry.troosters@med.kuleuven.be

\section{See linked article by Fastenau et al. on pg 425}

Physical activity is being increasingly recognised as a factor that modulates co-morbidities and adverse outcome in patients with COPD. ${ }^{1}$ Attention to physical inactivity is therefore of the utmost importance, particularly in patients who are not yet severely impaired by their lung function and are managed in primary care. Enhancing physical activity in these patients may have potential spin-offs, with important improvements in the burden of COPD co-morbidities. Many of the 'typical COPD co-morbidities' are indeed associated with lack of physical activity.

In this issue of the PCRJ, Fastenau and co-workers report low physical activity levels in a group of patients followed-up in primary care. $^{2}$ In these patients with GOLD stage I and II disease, 33\% of patients had a step count of around 5000 or less, which is conventionally seen as one of the benchmarks for 'sedentarism'3 ${ }^{3}$. This study is yet another call for action to healthcare providers managing these patients - patients who have, at first sight, 'mild to moderate' COPD. Measuring physical activity is no luxury reserved for lifestyle clubs. Physical activity should be considered a 'vital sign', ${ }^{4}$ and the study by Fastenau et al. shows this clearly.

The authors also conclude that there is a poor relation between exercise capacity - as assessed by the six minute walk test (6MWT) in this study - and physical activity. ${ }^{2}$ This poor relation can perhaps be explained to some extent by methodological factors in their study: possible selection bias with selection based on impaired exercise tolerance and low physical activity; for the 6MWT, the corridor not being of standard length and the possibility that there was no practice walking test; and, in terms of the activity monitor data and analysis, seasonal variation was not taken into account for the correlation analyses and there was no report of compliance with monitor use.

However, the poor relation between exercise capacity and physical activity behavior shown in this study ${ }^{2}$ should not come as a surprise. Leidy et al. speculated years ago that physical activity and functional capacity were two different concepts. ${ }^{5}$ When functional capacity is larger (i.e. there is better 6MWT performance) patients have more choice regarding engagement in physical activity. Physical activity is indeed a complex endpoint, influenced by several factors. The factors best understood intuitively are personal factors (including genetic), exercise-related factors, and psychological factors. Other factors influencing patients' choice whether or not to engage in physical activity are linked to interpersonal aspects (social support, as an example), environmental factors (climate, social environment and architectural) and policy (e.g. public transport, incentives for physical activity). ${ }^{6}$

So, in comparison with other studies performed in 'milder' (or primary care) COPD patients, ${ }^{7-9}$ the present study ${ }^{2}$ confirms for primary care practitioners that physical activity is low in many patients with COPD. Low physical activity levels are the best guarantee that patients will develop co-morbidity (on top of their many pack-years of smoking)..$^{10}$ What should one do next?

Firstly, assessment of physical activity is of the utmost importance. This is also what Fastenau and co-workers conclude. ${ }^{2}$ Questionnaires may help to identify severely inactive patients, ${ }^{11}$ but they largely fail to provide a correct reflection of physical activity across the whole spectrum. Physical activity monitors have become more readily available, and in the European IMI-JU PROactive project ( www.PROactiveCOPD) some of these monitors are identified as being valid tools for the assessment of physical activity in patients with COPD. ${ }^{12}$ The use of activity monitors in primary care has been proposed and validated by others. ${ }^{13}$ In the future, the use of smart phones containing accelerometers may help in profiling patients at little cost and, importantly, with low time investment.

Secondly, primary care physicians and healthcare providers in general should be aware of the risks of physical inactivity. An attributed mortality of around $10 \%$ cannot be underestimated..$^{14}$ All healthcare providers should be aware that inactive patients with COPD will eventually develop co-morbidities which will complicate significantly their disease management.

Lastly, enhancing physical activity is a challenge, and there is no 'miracle solution'. Simple interventions such as the use of pedometers with agreed physical activity targets may help patients to enhance physical activity levels. Increasingly, we will see health technology applications appear which promote physical activity. ${ }^{15}$ Pilot studies have been undertaken with these techniques in patients with mild COPD. Concerted efforts between healthcare providers, policy makers and social support initiatives are likely to be successful in the long term. ${ }^{16}$ One example is an initiative in Catalunia where, in collaboration with the city engineers, walking circuits were designed in the city to fit the needs of patients with COPD. ${ }^{17}$ The use of these walking trails did increase physical activity in patients who completed a pulmonary rehabilitation programme. Such community-based efforts should be fostered, since they may benefit not just patients with COPD but also patients with obesity or those at risk of developing Type II diabetes. Guidelines should exist at a local level on when and how to refer patients with COPD for physical activityenhancing interventions. Such guidelines do exist in the Netherlands, ${ }^{18}$ where the study by Fastenau et al. took place. In the absence of 
guidelines, the general guidelines from the Center for Disease Control in the USA ${ }^{4}$ could be used as a basis, and local policy makers should attempt to provide incentives (financial and other) to promote healthenhancing behavior, rather than focussing on treating the consequences of physical inactivity. Partial reimbursement of health club fees is a good example, an initiative which has been studied in patients with diabetes. ${ }^{19}$

In summary, Fastenau et al. should be complimented on their study which recruited patients from 20 general practices in the Netherlands. They clearly highlight the low and largely unpredictable physical activity levels in patients with COPD selected in primary care. Screening for physical activity in primary care should be considered, and action should be undertaken when patients are labeled as inactive. Despite the enthusiasm, healthcare providers should be aware that changing physical activity entails behaviour change, and inherent resistance to change may negatively impact on the success of interventions. Nevertheless, when successful the long-term health benefits for patients surely justify the efforts...

Conflicts of interest The author declares that he has no conflicts of interest in relation to this article.

Funding Flemish Research Foundation \#G.0871.13. TT is the PI of the IMI-JU 'PROactive project' \# 115011 www.PROactiveCOPD.com.

Commissioned article; not externally peer-reviewed; accepted 6th November 2013; online 23rd November 2013

(C) 2013 Primary Care Respiratory Society UK. All rights reserved

http://dx.doi.org/10.4104/pcrj.2013.00099

Prim Care Respir J 2013; 22(4): 391-392

\section{References}

1. Troosters T, van der Molen T, Polkey Ml et al. Improving physical activity in COPD: towards a new paradigm. Respir Res 2013;14:1-8

http://dx.doi.org/10.1186/1465-9921-14-115

2. Fastenau A, van Schayck OCP, Gosselink R, PM Aretz K, Muris JWM. Discrepancy between functional exercise capacity and daily physical activity: a cross-sectional study in patients with mild to moderate COPD. Prim Care Respir J 2013;22(4):42530. http://dx.doi.org/10.4104/pcrj.2013.00090

3. Tudor-Locke C, Craig CL, Thyfault JP, Spence JC. A step-defined sedentary lifestyle index: <5000 steps/day. Appl Physiol Nutr Metab 2013;38:100-14. http://dx.doi.org/10.1139/apnm-2012-0235

4. National Physical Activity Plan. National Physical Activity Plan for the United States. 1-5-2010. Internet Communication: http://www.physicalactivityplan.org/
NationalPhysicalActivityPlan.pdf

5. Leidy NK. 1994. Using functional status to assess treatment outcomes. Chest 106:1645-6. http://dx.doi.org/10.1378/chest.106.6.1645

6. Bauman AE, Reis RS, Sallis JF, Wells JC, Loos RJ, Martin BW. Correlates of physical activity: why are some people physically active and others not? Lancet 2012;380:258-71. http://dx.doi.org/10.1016/S0140-6736(12)60735-1

7. Watz H, Waschki B, Meyer T, Magnussen H. Physical activity in patients with COPD. Eur Respir J 2009;33:262-72. http://dx.doi.org/10.1183/09031936.00024608

8. Shrikrishna D, Patel M, Tanner RJ et al. Quadriceps wasting and physical inactivity in patients with COPD. Eur Respir J 2012;40:1115-22. http://dx.doi.org/10.1183/09031936.00170111

9. Van Remoortel $\mathrm{H}$, Hornikx M, Demeyer $\mathrm{H}$, et al. Daily physical activity in subjects with newly diagnosed COPD. Thorax 2013;68:962-3. http://dx.doi.org/10.1136/thoraxjnl-2013-203534

10. Van Remoortel H, Hornikx M, Langer D, et al. Risk Factors and Comorbidities in the Pre-Clinical Stages of Chronic Obstructive Pulmonary Disease Am J Respir Crit Care Med 2013;in press. http://www.dx.doi.org/10.1164/rccm.201307-12400C

11. Garfield BE, Canavan JL, Smith CJ, et al. Stanford Seven-Day Physical Activity Recall questionnaire in COPD. Eur Respir J 2012;40:356-62. http://dx.doi.org/10.1183/09031936.00113611

12. Rabinovich RA, Louvaris Z, Raste $Y$ et al. Validity of physical activity monitors during daily life in patients with COPD. Eur Respir J 2013;42:1205-15. http://dx.doi.org/10.1183/09031936.00134312

13. Winzenberg T,Shaw KA. Screening for physical inactivity in general practice - a test of diagnostic accuracy. Aust Fam Physician 2011;40:57-61.

14. Lee IM, Shiroma EJ, Lobelo F, Puska P, Blair SN, Katzmarzyk PT. Effect of physical inactivity on major non-communicable diseases worldwide: an analysis of burden of disease and life expectancy. Lancet 2012;380:219-29. http://dx.doi.org/10.1016/S0140-6736(12)61031-9

15. Moy ML, Weston NA, Wilson EJ, Hess ML, Richardson CR. A pilot study of an Internet walking program and pedometer in COPD. Respir Med 2012;106:134250. http://dx.doi.org/10.1016/j.rmed.2012.06.013

16. Kohl HW III, Craig CL, Lambert EV, et al. The pandemic of physical inactivity: global action for public health. Lancet 2012;380:294-305. http://dx.doi.org/10.1016/S0140-6736(12)60898-8

17. Pleguezuelos E, Perez ME, Guirao L, et al. Improving physical activity in patients with COPD with urban walking circuits. Respir Med 2013;in press. http://dx.doi.org/10.1016/j.rmed.2013.07.008

18. Langer D, Hendriks E, Burtin C, et al. A clinical practice guideline for physiotherapists treating patients with chronic obstructive pulmonary disease based on a systematic review of available evidence. Clin Rehabil 2009;23:445-62. http://dx.doi.org/10.1177/0269215509103507

19. Pahor M. Consideration of insurance reimbursement for physical activity and exercise programs for patients with diabetes. JAMA 2011;305:1808-09. http://dx.doi.org/10.1001/jama.2011.572

\section{Available online at http://www.thepcrj.org}

